\title{
Wnt3a activates $\beta 1$-integrin and regulates migration and adhesion of vascular smooth muscle cells
}

\author{
XIAOLIN WU ${ }^{1,2^{*}}$, JICHUN WANG $^{1 *}$, HONG JIANG $^{1}$, QI HU $^{1}$, JING CHEN $^{1}$,

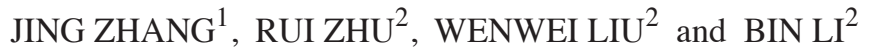 \\ ${ }^{1}$ Department of Cardiology, Renmin Hospital of Wuhan University, Wuhan, Hubei 430060; ${ }^{2}$ Department of Cardiology, \\ Xiangyang Central Hospital, Affiliated Hospital of Hubei University of Arts and Science, Xiangyang, Hubei 441000, P.R. China
}

Received June 8, 2013; Accepted January 27, 2014

DOI: $10.3892 / \mathrm{mmr} .2014 .1937$

\begin{abstract}
Vascular smooth muscle cells (VSMCs) are known to undergo functional changes that contribute to the pathogenesis of atherosclerosis and restenosis. Wnts are a family of secreted glycoproteins that bind to transmembrane Frizzled receptors and initiate signaling cascades with indispensable roles during cell migration, adhesion, proliferation, and survival. The present study reports that wingless-type MMTV integration site family, member 3a (Wnt3a) activates the canonical Wnt pathway in rat VSMCs by triggering the phosphorylation of $\beta$-catenin at position Ser675 and GSK-3 $\beta$ at position Ser9. Phosphorylation of these two proteins increases VSMC migration and adhesion. In a search for the downstream mediators of Wnt3a's effects on VSMC migration and adhesion, Wnt3a treatment was observed to increase integrin-linked kinase (ILK) protein expression. ILK is a serine/threonine protein kinase that is thought to control cell migration and adhesion by regulating the affinity of $\beta 1$-integrin for the extracellular matrix. Wnt3a treatment of VSMCs also activated $\beta 1$-integrin without changing the quantity of protein expressed on the cell surface. These results demonstrate that Wnt3a enhances migration and adhesion of VSMCs by activating $\beta 1$-integrin.
\end{abstract}

\section{Introduction}

Signaling by members of the wingless-type MMTV integration site (Wnt) family of proteins controls various cellular and biological processes, ranging from cell adhesion, cell migration, and cancer development to differentiation of multiple cell lineages, cell polarity, and stem cell self-renewal (1). The majority of research on Wnts has focused on the

Correspondence to: Dr Hong Jiang, Department of Cardiology, Renmin Hospital of Wuhan University, 99 Ziyang Road, Wuhan, Hubei 430060, P.R. China

E-mail: jiang_hongw@yahoo.com.cn

*Contributed equally

Key words: adhesion, $\beta 1$-integrin, migration, vascular smooth muscle cells, wingless-type MMTV integration site family, member $3 \mathrm{a}$
Wnt/ $\beta$-catenin pathway, previously referred to as the canonical Wnt pathway. Activation of the canonical Wnt pathway leads to nuclear translocation of $\beta$-catenin, which binds to lymphoid enhancer-binding factor/T cell-specific transcription factor (LEF/TCF) and activates transcription of target genes (1-3). The stability of $\beta$-catenin is also regulated by integrin-linked kinase (ILK), a serine/threonine protein kinase that interacts with the cytoplasmic domains of $\beta 1$ and $\beta 3$ integrins. Integrins composed of $\alpha$ and $\beta$ transmembrane subunits are bidirectional signaling molecules. Inside-out signaling by integrins occurs when direct interactions between the cytoplasmic tail of $\beta$-subunits and the cytoskeletal protein, talin, regulate the affinity for the ligand. Following ligand binding, integrins engage in outside-in signaling by recruiting signaling and adaptor proteins to the cytoplasmic tail of the $\alpha$ and/or $\beta$ subunits. This recruitment results in actin reorganization and modulation of various intracellular signaling pathways $(4,5)$. ILK-integrin interactions organize the connections of the extracellular matrix (ECM) to the cytoskeleton and, by doing so, regulate cell migration and adhesion. In addition, ILK activity links integrin function to Wnt signaling (6-9). At present, in vitro and in vivo evidence supports the hypothesis that phosphorylation by ILK stimulates $\beta$-catenin to translocate into the nucleus and form a complex with LEF. In addition, ILK phosphorylates and inactivates glycogen synthase kinase-3 $\beta$ (GSK-3 $\beta$ ). Inactivation of GSK-3 $\beta$ eventually results in activation of canonical Wnt target genes (6-10). However, little is known about how Wnt/ $\beta$-catenin signaling activates ILK or integrin signaling. In the current study, we activated the canonical Wnt signaling by recombinant Wnt3a to investigate the migration and adhesion ability of vascular smooth muscle cells (VSMCs) and the role of ILK and $\beta 1$-integrin.

\section{Materials and methods}

Cell culture and reagents. Primary VSMCs were isolated from the thoracic aorta of male Sprague Dawley rats (weight, 100-150 g), and then cultured in Dulbecco's modified Eagle's medium (DMEM) containing 10\% fetal bovine serum (FBS; Hyclone, Logan, UT, USA), $100 \mathrm{U} / \mathrm{ml}$ penicillin and $100 \mu \mathrm{g} / \mathrm{ml}$ streptomycin (Beyotime, Shanghai, China). The cells were incubated at $37^{\circ} \mathrm{C}$ in a humidified atmosphere of $95 \%$ air and $5 \%$ $\mathrm{CO}_{2}$. The purity of the VSMCs was estimated to be $\sim 90 \%$, 
based on cell morphology and the results of immunostaining with monoclonal mouse anti- $\alpha$-actin antibodies (Sigma-Aldrich, St. Louis, MO, USA). The VSMCs used for all experiments were between the 3rd and 6th passages. Recombinant Wnt3a was purchased from R\&D Systems (Minneapolis, MN, USA). In this study, anti- $\beta$-catenin antibody (polyclonal, rabbit) and anti-phospho- $\beta$-catenin (Ser675) antibody (polyclonal, rabbit; both from Cell Signaling Technology Inc., Danvers, MA, USA), anti-GSK-3 $\beta$ antibody (polyclonal, rabbit), anti-phospho-GSK-3 $\beta$ (Ser9) antibody (polyclonal, goat) and anti- $\beta$-actin antibody (polyclonal, rabbit; Santa Cruz Biotechnology, Inc., Santa Cruz, CA, USA), anti-ILK antibody (polyclonal, rabbit; Sigma-Aldrich, St. Louis, MO, USA), anti- $\beta 1$-integrin antibody (monoclonal, rabbit) and anti-active- $\beta 1$-integrin antibody (monoclonal, mouse; both from Millipore, Billerica, MA, USA) were used.

Transwell migration assay. The VSMC migration assay was performed using transwell cell culture inserts (Transwell Assay system; Corning Inc., Acton, MA, USA) for 24-well plates. A total of $100 \mu \mathrm{l}$ VSMCs $\left(3 \times 10^{5}\right.$ cells $\left./ \mathrm{ml}\right)$ suspended in serum-free DMEM was added to the upper polycarbonate membrane insert (pore size, $8 \mu \mathrm{m}$ ), Wnt3a (final concentration, $100 \mathrm{ng} / \mathrm{ml}$ ) was added to the upper chamber and $600 \mu \mathrm{l}$ culture medium containing $10 \%$ FBS was added to the lower chamber. The cells were allowed to migrate for $24 \mathrm{~h}$ while the plates were incubated in a humidified incubator in a $5 \% \mathrm{CO}_{2}$ atmosphere at $37^{\circ} \mathrm{C}$. After $24 \mathrm{~h}$, the cells that remained on the upper surface of the membrane were removed with a cotton swab. The membrane was fixed with anhydrous methanol for $20 \mathrm{~min}$ at room temperature and then stained with $0.1 \%$ crystal violet for $15 \mathrm{~min}$. A microscope (Nikon, Tokyo, Japan) was used to determine the number of migratory cells by counting the cells in five randomly selected fields of view. All experiments were performed in triplicate.

Wound healing assay. VSMCs were plated in 6-well plates and grown to $70-80 \%$ confluency. The experimental wounds were created by dragging $200 \mu \mathrm{l}$ pipette tips across the bottom of the cell culture wells. The cells were rinsed with phosphate-buffered saline (PBS) and the culture medium was replaced with fresh maintenance medium supplemented with Wnt3a (final concentration; $100 \mathrm{ng} / \mathrm{ml}$ ). The wound healing was recorded after $48 \mathrm{~h}$ using bright field microscopy. The wound gap was measured and the percentage of wound repair was determined.

Cell adhesion assay. The cell adhesion assay was performed as described previously $(11,12)$. Ninety-six-well tissue culture plates (Costar, Corning Inc.) were coated overnight at $4{ }^{\circ} \mathrm{C}$ with collagen type I (Sigma-Aldrich; $20 \mu \mathrm{g} / \mathrm{ml}$ ). After washing with PBS, the plates were blocked with PBS containing $1 \%$ heat-denatured bovine serum albumin for $1 \mathrm{~h}$ at room temperature. The plates were washed extensively with serum-free DMEM, and $3 \times 10^{4}$ VSMCs were plated and incubated with Wnt3a (final concentration, $100 \mathrm{ng} / \mathrm{ml}$ ) for $1 \mathrm{~h}$ at $37^{\circ} \mathrm{C}$. After washing with PBS, the cells were fixed with $4 \%$ paraformaldehyde for $30 \mathrm{~min}$ at room temperature and stained with $0.5 \%$ toluidine blue for $15 \mathrm{~min}$. The plates were washed extensively with double distilled water. A microscope (Nikon) was used to determine the number of adherent cells by counting the cells in five randomly selected fields of view. The cells were solubilized in $1 \%$ sodium dodecyl sulfate (SDS) and quantified using a microtiter plate reader set at 590 nm (Tecan, Männedorf, Switzerland).

Western blot analysis. VSMCs were harvested following treatment with Wnt3a(final concentration; $100 \mathrm{ng} / \mathrm{ml}$ ) or PBS (control) for three days. The cells were lysed by incubation with radioimmunoprecipitation (RIPA) buffer supplemented with proteinase inhibitors for $30 \mathrm{~min}$ on ice. Equal quantities of protein were separated by SDS-polyacrylamide gel electrophoresis (PAGE) and subjected to immunoblot analysis according to standard protocols. The separated proteins were blotted onto nitrocellulose membranes and incubated with antibodies that recognize total $\beta$-catenin, phospho- $\beta$-catenin (Ser675), total GSK-3 $\beta$, phospho-GSK-3 $\beta$ (Ser9), $\beta 1$-integrin, ILK and $\beta$-actin overnight at $4^{\circ} \mathrm{C}$. Following three washes, the blots were incubated with peroxidase-conjugated secondary antibodies (Boster, Wuhan, China) for $1 \mathrm{~h}$ at room temperature and subsequently analyzed using an enhanced chemiluminescence detection system (Clinx, Shanghai, China).

Flow cytometric analysis. VSMCs were serum starved for $24 \mathrm{~h}$ and supplemented with Wnt3a (final concentration, $100 \mathrm{ng} / \mathrm{ml}$ ) for three days. $\beta 1$-integrin expression on the surface of the VSMCs was evaluated by using indirect immunofluorescence and flow cytometry. Following washing with PBS, the cells were incubated with a rabbit anti-rat $\beta 1$-integrin antibody (dilution; $1: 70$ ) and a mouse anti-rat active $\beta 1$-integrin antibody (dilution; 1:200) for $30 \mathrm{~min}$ at room temperature in the dark. The cells were washed again and incubated with phycoerythrin-conjugated goat anti-rabbit IgG (dilution, 1:50; Bioss, Beijing, China) and Cy3-conjugated goat anti-mouse IgG (dilution, 1:50; Bioss) secondary antibodies for $45 \mathrm{~min}$. Following incubation with secondary antibodies, the cells were analyzed by flow cytometry with a Becton-Dickinson FACS Calibur and Cell Quest software (BD, Franklin Lakes, NJ, USA).

Statistical analysis. Paired or independent t-tests were performed for statistical analyses of all data. $\mathrm{P}<0.05$ was considered to indicate a statistically significant difference. The data are expressed as the mean \pm standard error of the mean.

\section{Results}

Wnt3a promotes VSMC migration. Transwell migration and wound healing assays were performed to investigate the effect of Wnt3a treatment on VSMC migration. The migratory ability of VSMCs treated with Wnt3a was significantly increased in the transwell migration assay (Fig. 1A). Following $24 \mathrm{~h}$ incubation, the number of cells that migrated across the polycarbonate membrane was higher in the Wnt3a group compared with the control group $(\mathrm{P}<0.05)$. As shown in Fig. 1B, VSMCs treated with Wnt3a moved faster than the control cells. These results demonstrate that Wnt3a treatment induces VSMC migration.

Adhesion of VSMCs to collagen type I. To investigate the influence of Wnt3a on cell-matrix interactions, adhesion assays were performed. Cells were stained with toluidine blue and the microplate reader method was used to monitor cell adhesion. The results demonstrated that the number of VSMCs 
A

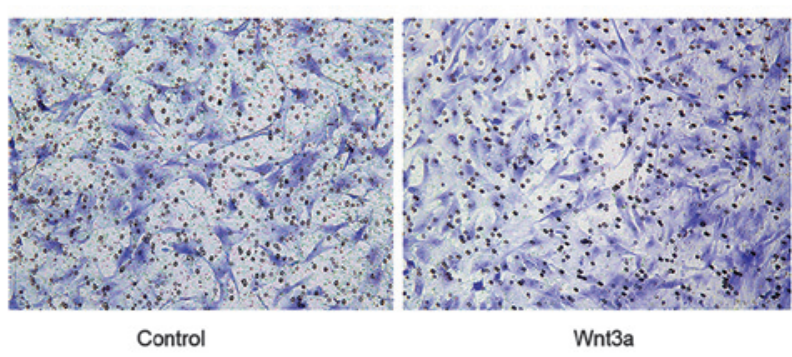

B
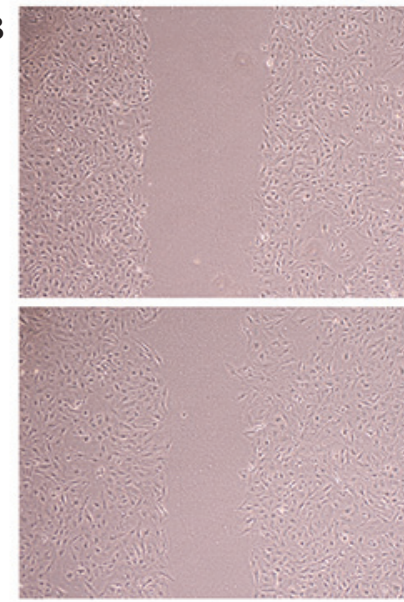

Control
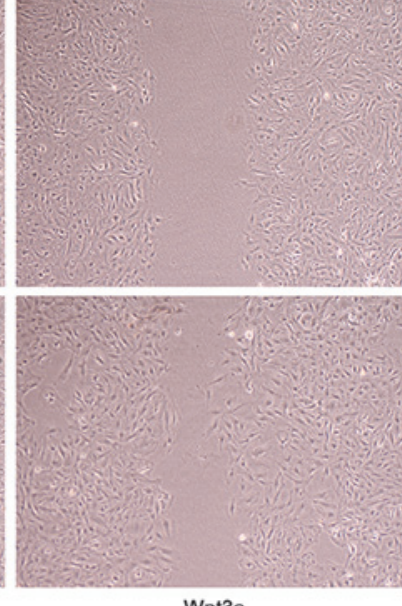
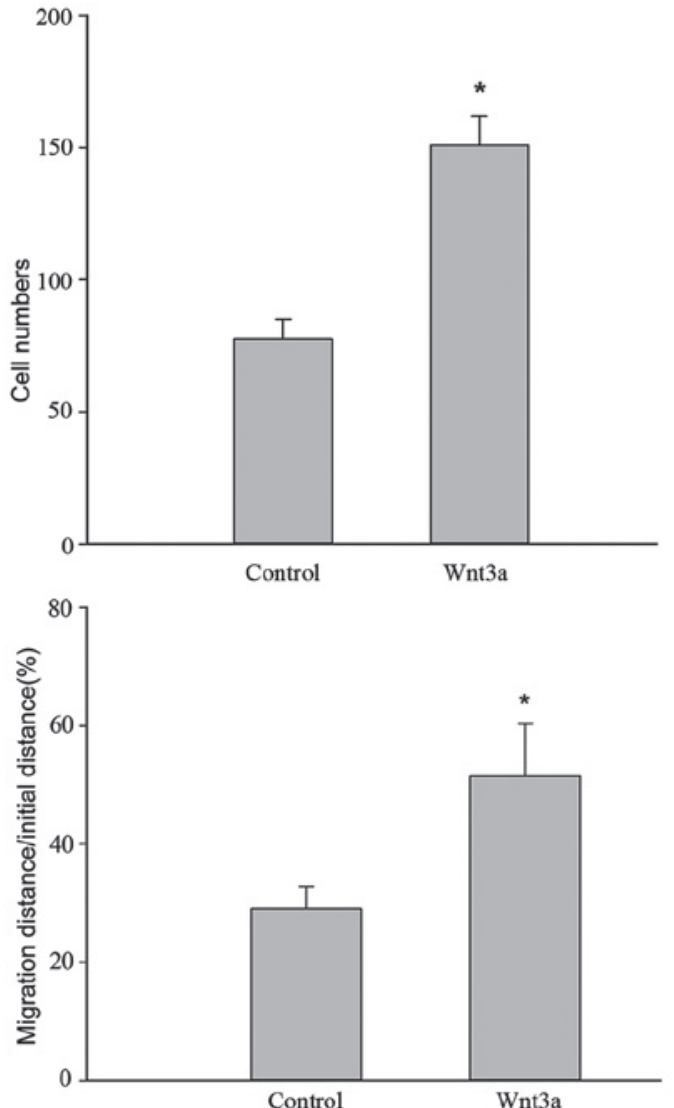

Figure 1. Wnt3a promotes VSMC migration. (A) Transwell migration assay. VSMCs on transwell inserts were stained with $0.1 \%$ crystal violet (left panel; magnification, x200). The number of migratory VSMCs was significantly higher in the Wnt3a-treated group compared with the phosphate-buffered saline-treated group (right panel; " $\mathrm{P}<0.05$ vs. control). (B) A wound healing assay demonstrated that treatment with Wnt3a increased the migratory ability of VSMCs (left panel; magnification, $\mathrm{x} 40$ ). The migration distance of VSMCs treated with Wnt3a was significantly higher compared with control cells (right panel; " $\mathrm{P}<0.05$, vs. control). VSMCs, vascular smooth muscle cells; Wnt3a, wingless-type MMTV integration site family, member 3a.
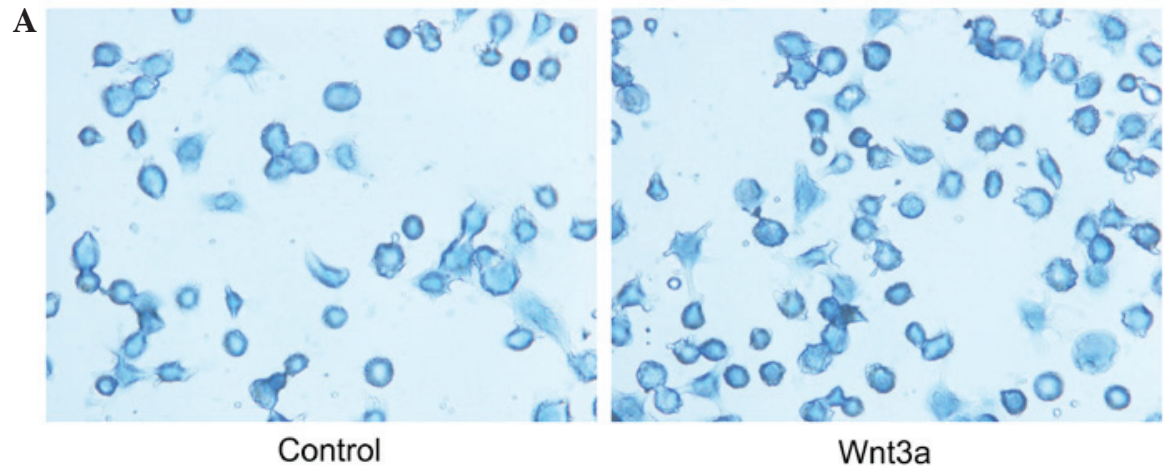

Wnt3a
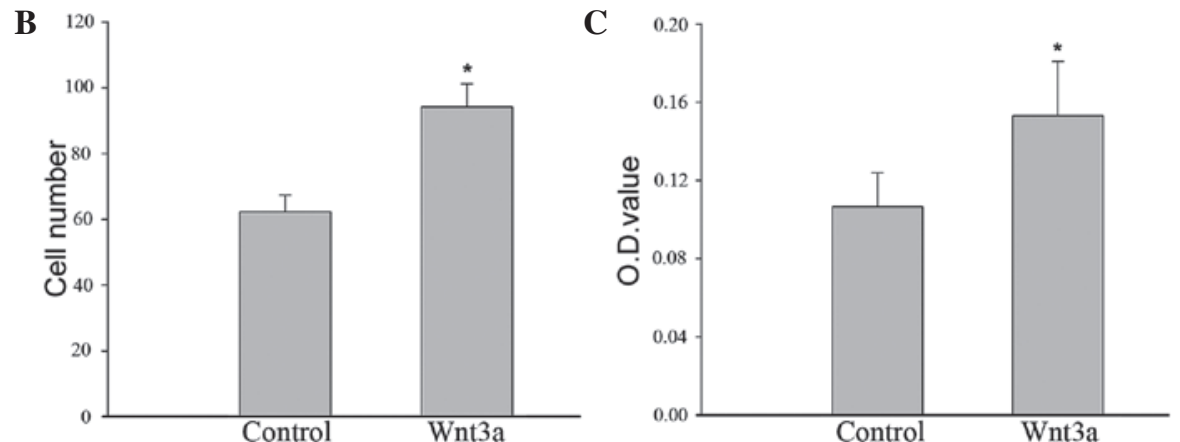

Figure 2. VSMC adhesion to collagen type I. (A) VSMCs that were cultured on plates were stained with toluidine blue (magnification, $\mathrm{x} 400$ ). (A and B) Wnt3a treatment increased VSMC adhesion to collagen type I. Cell adhesion was estimated by measuring the absorbance at $590 \mathrm{~nm}$. (C) The optical density value was higher in samples from the Wnt3a-treated group than in those from the control group " $\mathrm{P}<0.05$, vs. control. VSMCs, vascular smooth muscle cells; Wnt3a, wingless-type MMTV integration site family, member 3a. 
A
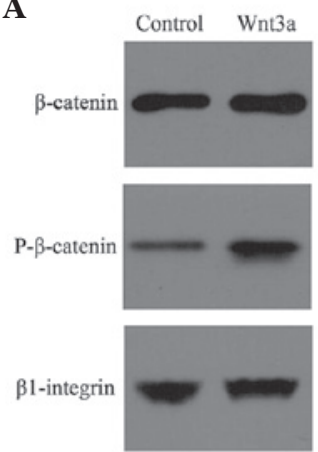

$\beta$-actin

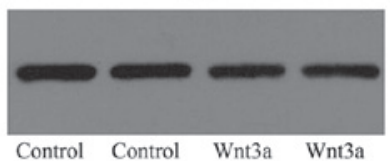

B
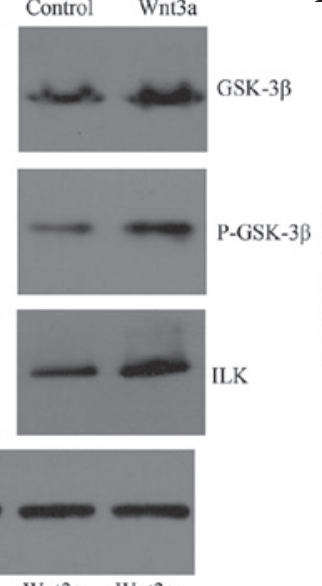

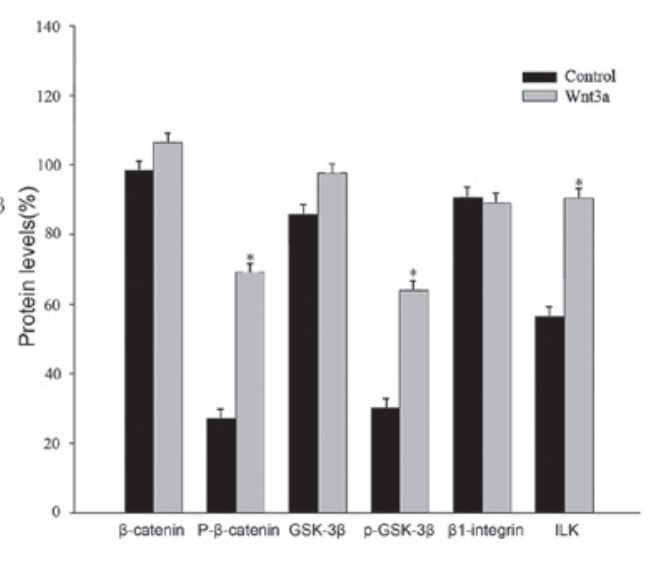

Figure 3. Protein expression was measured in cultured rat VSMCs that were treated with recombinant Wnt3a or phosphate-buffered saline (control) for three days. (A) Western blot analysis showing total $\beta$-catenin, phospho- $\beta$-catenin (Ser675), total GSK-3 $\beta$, phospho-GSK-3 $\beta$ (Ser9), $\beta 1$-integrin, and ILK protein expression in control and Wnt3a-treated cells. (B) The phospho- $\beta$-catenin and phospho-GSK-3 $\beta$ protein signals were normalized to those of total $\beta$-catenin and total GSK-3 $\beta$, respectively. The $\beta 1$-integrin and ILK protein signals were quantified and normalized to that of $\beta$-actin ("P<0.05, vs. control). GSK-3 $\beta$, glycogen synthase kinase 3ß; ILK, integrin-linked kinase; P-, phosphorylated; VSMCs, vascular smooth muscle cells; Wnt3a, wingless-type MMTV integration site family, member 3a.

A
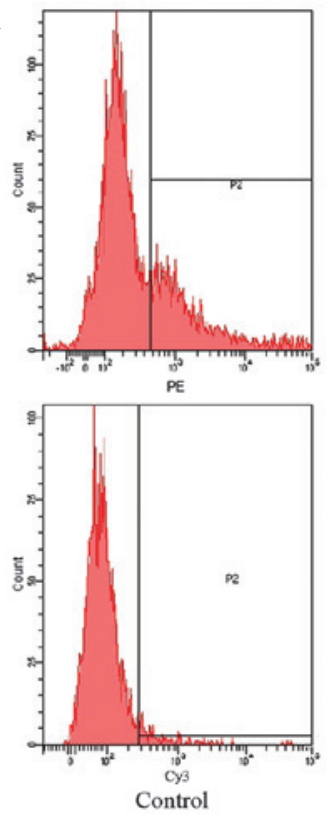
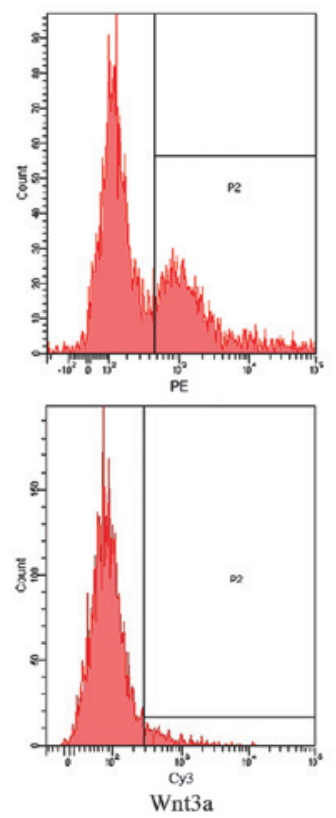

B

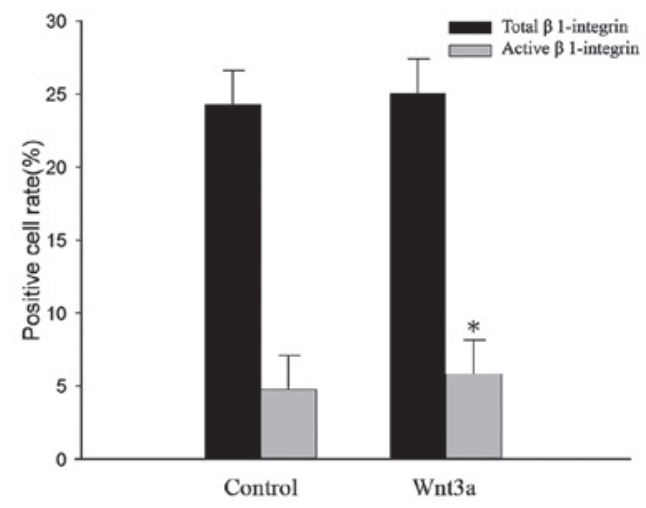

Figure 4. Wnt3a activates $\beta 1$-integrin. (A) Active $\beta 1$-integrin and total $\beta 1$-integrin expression on the surface of VSMCs was evaluated by flow cytometry. (B) Treatment with Wnt3a activated $\beta 1$-integrin but did not affect the expression levels on the cell surface ("P<0.05, vs. control). VSMCs, vascular smooth muscle cells; Wnt3a, wingless-type MMTV integration site family, member 3a.

that adhered to collagen type I was significantly greater in the Wnt3a-treated group compared with the control group. In addition, the optical density value detected by the microplate reader was higher in the samples from the Wnt3a-treated group compared with those from the control group (Fig. 2). These results indicate that $\mathrm{Wnt} 3 \mathrm{a}$ treatment significantly improves the adhesion of VSMCs to collagen type I.

Wnt 3 a regulates protein expression. Wnt $3 \mathrm{a}$ is a prominent member of the Wnt family and may induce the accumulation of $\beta$-catenin and activate the canonical Wnt pathway (13). To understand the mechanisms by which Wnt3a affects
VSMCs, the protein expression of $\beta$-catenin, GSK-3 $\beta$, ILK, and $\beta 1$-integrin were analyzed, all of which are either components of, or targets of the canonical Wnt signaling pathway. Treatment of VSMCs with Wnt3a upregulated the expression of phospho- $\beta$-catenin (Ser675), phospho-GSK-3 $\beta$ (Ser9), and ILK; however, the expression of total $\beta$-catenin, total GSK-3 $\beta$, and $\beta 1$-integrin was not significantly different between the two groups (Fig. 3).

Wnt3a activates $\beta 1$-integrin. Since treatment with Wnt3a did not alter the expression of $\beta 1$-integrin, the expression of active $\beta 1$-integrin on the surface of VSMCs was quantified using flow 
cytometry (Fig. 4A). The anti-active- $\beta 1$-integrin antibody is specific for the active conformation of rat $\beta 1$-integrin, and it may also discriminate between the activated states. Therefore, it is useful to investigate how $\beta 1$-integrin activation is regulated. VSMCs that were stimulated with Wnt3a for three days bound more active- $\beta 1$-integrin antibodies compared with the unstimulated cells. However, Wnt3a treatment had no effect on the total quantity of $\beta 1$-integrin expression on the surface of VSMCs. These results demonstrate that Wnt3a treatment activates $\beta 1$-integrin without changing its expression levels (Fig. 4).

\section{Discussion}

It is well known that the Wnt signaling pathways affect migration and adhesion via downstream effectors (14-18). The canonical Wnt pathway controls cell migration and adhesion by regulating the stability of $\beta$-catenin, the major downstream target of Wnt signaling (14-18). Previous studies have determined a multitude of points of crosstalk between the Wnt pathways and the mechanisms that control cellular architecture, from the level of receptors to the level of transcription. Cellular mechanisms that are responsible for the regulation of migration and adhesion also function to modulate the activity of several Wnt pathway components $(14,19,20)$. Activation of $\beta$-catenin signaling may occur by inhibition of GSK-3 $\beta$ and GSK-3 $\beta$-mediated phosphorylation of residues in the $\mathrm{N}$-terminal region of $\beta$-catenin may lead to rapid degradation. However, $\beta$-catenin is also activated by phosphorylation of serine 675 , in the C-terminal region of the protein. This phosphorylation facilitates the nuclear translocation of $\beta$-catenin and enhances its transcriptional activity, as has been shown to occur in VSMCs in vitro upon activation by v-akt murine thymoma viral oncogene homolog 1 (Akt) or cAMP-dependent protein kinase, catalytic subunit $\mathrm{C} \alpha$ (PKA) (20-23). Enhanced $\beta$-catenin phosphorylation at Ser675 and enhanced GSK-3 $\beta$ phosphorylation at Ser9 in rat VSMCs were observed following Wnt3a treatment. Phosphorylation of GSK-3 $\beta$ at Ser9 may inactivate the protein. Therefore, although a role of PKA, Akt, or other signaling pathways in $\beta$-catenin phosphorylation may not be excluded, the current data suggest that stimulation of VSMCs with Wnt3a activates the Wnt/ $\beta$-catenin pathway.

VSMC migration and proliferation contribute to arterial wound repair and thickening of the intimal layer in atherosclerosis and restenosis. These processes are influenced by cell adhesion to molecules present in the ECM and are regulated by the integrin family of cell-surface matrix receptors. An important signaling molecule acting downstream of integrin receptors is ILK. ILK has been implicated in the control of cancer cell growth and survival through modulation of downstream targets, notably Akt and GSK-3 $\beta$ (24-26). Evidence also exists to establish ILK as a molecular adaptor protein linking integrins to the actin cytoskeleton and regulating actin polymerization $(8,24-27)$. In vitro, ILK may phosphorylate and inactivate GSK-3 $\beta$ to promote the nuclear accumulation of $\beta$-catenin and activation of the canonical Wnt pathway (6-10). However, it remains unclear how activation of the canonical Wnt pathway influences the activity of ILK. In the current study, the role of the canonical Wnt pathway in ILK activation was investigated by culturing rat VSMCs with recombinant
Wnt3a, and assessing ILK protein expression and $\beta 1$-integrin activity. The results demonstrate that Wnt3a, not only activates the canonical Wnt pathway, but also increases ILK protein expression and $\beta 1$-integrin activity.

The present study also demonstrates that treatment with Wnt3a significantly increases VSMC migration and adhesion. Cell adhesion to the ECM via integrins triggers the assembly of the actin cytoskeleton and regulatory proteins that form a large multiprotein complex. Through their association with the actin cytoskeleton and signaling molecules, adhesion complexes generate elaborate networks that control a variety of cellular processes in normal and pathological conditions, including cell migration, proliferation, survival, and also invasion and metastasis (28-31). Adhesion of VSMCs to collagen type I has been shown to be $\beta 1$-integrin-dependent $(11,32)$. Although adhesion of VSMCs to collagen type I is predominantly mediated via $\beta 1$-integrin receptors, the cell surface expression levels of $\beta 1$-integrin were not altered by Wnt3a stimulation (33). As demonstrated by flow cytometry, Wnt3a treatment activated $\beta 1$-integrin in rat VSMCs. The mechanism by which intracellular signals alter the affinity and avidity of integrin receptors, termed 'inside-out' signaling, has been characterized by several groups $(4,5,34)$. ILK is known to bind to the cytoplasmic domain of integrin subunits. This binding either increases affinity by triggering conformational changes in the integrin subunits or increases avidity by stimulating integrin clustering in the cell membrane $(8,24-27)$. The results of the current study lead to the conclusion that Wnt3a activates ILK and $\beta 1$-integrin, which then regulates VSMC migration and adhesion.

In conclusion, the Wnt/ $\beta$-catenin pathway in rat VSMCs has been observed to activate $\beta 1$-integrin without leading to quantitative changes in its expression on the cell surface. ILK binds to $\beta 1$-integrin to increase the affinity of $\beta 1$-integrin for the ECM by inside-out signaling, which may increase cell migration and adhesion. Wnt3a has been observed to regulate the migration and adhesion of VSMCs, and may therefore be a valuable therapeutic target for the prevention and treatment of vascular disease. However, vascular disease is a complicated process that is modulated by multiple signaling pathways. Future studies should investigate the mechanisms and functions of Wnt3a signaling in other cell lines and model systems.

\section{Acknowledgements}

This study was supported by the National Science Foundation of China (grant nos. 81170195 and 81200156). The authors would like to thank all teachers from the Renmin Hospital of Wuhan University for their technical assistance.

\section{References}

1. van de Schans VA, Smits JF and Blankesteijn WM: The Wnt/frizzled pathway in cardiovascular development and disease: friend or foe? Eur J Pharmacol 585: 338-345, 2008.

2. Rao TP and Kühl M: An updated overview on Wnt signaling pathways: a prelude for more. Circ Res 106: 1798-1806, 2010.

3. Tsaousi A, Mill C and George SJ: The Wnt pathways in vascular disease: lessons from vascular development. Curr Opin Lipidol 22: 350-357, 2011.

4. Montanez E, Ussar S, Schifferer M, et al: Kindlin-2 controls bidirectional signaling of integrins. Genes Dev 22: 1325-1330, 2008. 
5. Kim C, Ye F and Ginsberg MH: Regulation of integrin activation. Annu Rev Cell Dev Biol 27: 321-345, 2011.

6. Schambony A, Kunz M and Gradl D: Cross-regulation of Wnt signaling and cell adhesion. Differentiation 72: 307-318, 2004

7. Oloumi A, McPhee T and Dedhar S: Regulation of E-cadherin expression and beta-catenin/Tcf transcriptional activity by the integrin-linked kinase. Biochim Biophys Acta 1691: 1-15, 2004.

8. Hannigan G, Troussard AA and Dedhar S: Integrin-linked kinase: a cancer therapeutic target unique among its ILK. Nat Rev Cancer 5: 51-63, 2005.

9. Rallis C, Pinchin SM and Ish-Horowicz D: Cell-autonomous integrin control of Wnt and Notch signalling during somitogenesis. Development 137: 3591-3601, 2010.

10. Oloumi A, Syam S and Dedhar S: Modulation of Wnt3a-mediated nuclear beta-catenin accumulation and activation by integrin-linked kinase in mammalian cells. Oncogene 25: 7747-7757, 2006.

11. Blaschke F, Stawowy P, Goetze S, et al: Hypoxia activates beta(1)-integrin via ERK $1 / 2$ and p38 MAP kinase in human vascular smooth muscle cells. Biochem Biophys Res Commun 296: 890-896, 2002.

12. Stringa E, Knäuper V, Murphy G and Gavrilovic J: Collagen degradation and platelet-derived growth factor stimulate the migration of vascular smooth muscle cells. J Cell Sci 113: 2055-2064, 2000.

13. Bao XL, Song H, Chen Z and Tang X: Wnt3a promotes epithelial-mesenchymal transition, migration, and proliferation of lens epithelial cells. Mol Vis 18: 1983-1990, 2012.

14. Amin N and Vincan E: The Wnt signaling pathways and cell adhesion. Front Biosci (Landmark Ed) 17: 784-804, 2012

15. Nelson WJ and Nusse R: Convergence of Wnt, beta-catenin, and cadherin pathways. Science 303: 1483-1487, 2004.

16. Tan CW, Gardiner BS, Hirokawa Y, Layton MJ, Smith DW and Burgess AW: Wnt signalling pathway parameters for mammalian cells. PLoS One 7: e31882, 2012.

17. Parmalee NL and Kitajewski J: Wnt signaling in angiogenesis. Curr Drug Targets 9: 558-564, 2008.

18. Samarzija I, Sini P, Schlange T, Macdonald G and Hynes NE: Wnt3a regulates proliferation and migration of HUVEC via canonical and non-canonical Wnt signaling pathways. Biochem Biophys Res Commun 386: 449-454, 2009.

19. Nusse R: Wnt signaling in disease and in development. Cell Res 15: 28-32, 2005.

20. Brembeck FH, Rosário M and Birchmeier W: Balancing cell adhesion and Wnt signaling, the key role of beta-catenin. Curr Opin Genet Dev 16: 51-59, 2006.

21. Marchand A, Atassi F, Gaaya A, et al: The Wnt/beta-catenin pathway is activated during advanced arterial aging in humans. Aging Cell 10: 220-232, 2011.
22. Taurin S, Sandbo N, Yau DM, Sethakorn N and Dulin NO Phosphorylation of beta-catenin by PKA promotes ATP-induced proliferation of vascular smooth muscle cells. Am J Physiol Cell Physiol 294: C1169-C1174, 2008.

23. Mill C and George SJ: Wnt signalling in smooth muscle cells and its role in cardiovascular disorders. Cardiovasc Res 95: 233-240, 2012.

24. Ho B, Hou G, Pickering JG, Hannigan G, Langille BL and Bendeck MP: Integrin-linked kinase in the vascular smooth muscle cell response to injury. Am J Pathol 173: 278-288, 2008.

25. Ho B and Bendeck MP: Integrin linked kinase (ILK) expression and function in vascular smooth muscle cells. Cell Adh Migr 3: 174-176, 2009.

26. McDonald PC, Fielding AB and Dedhar S: Integrin-linked kinase - essential roles in physiology and cancer biology. J Cell Sci 121: 3121-3132, 2008 .

27. Hannigan GE, Coles JG and Dedhar S: Integrin-linked kinase at the heart of cardiac contractility, repair, and disease. Circ Res 100: 1408-1414, 2007

28. Huttenlocher A and Horwitz AR: Integrins in cell migration. Cold Spring Harb Perspect Biol 3: a005074, 2011.

29. Wang HQ, Bai L, Shen BR, Yan ZQ and Jiang ZL: Coculture with endothelial cells enhances vascular smooth muscle cell adhesion and spreading via activation of betal-integrin and phosphatidylinositol 3-kinase/Akt. Eur J Cell Biol 86: 51-62, 2007.

30. Carlson TR, Hu H, Braren R, Kim YH and Wang RA: Cell-autonomous requirement for betal integrin in endothelial cell adhesion, migration and survival during angiogenesis in mice. Development 135: 2193-2202, 2008.

31. Parsons JT, Horwitz AR and Schwartz MA: Cell adhesion: integrating cytoskeletal dynamics and cellular tension. Nat Rev Mol Cell Biol 11: 633-643, 2010.

32. Kappert K, Schmidt G, Doerr G, Wollert-Wulf B, Fleck E and Graf K: Angiotensin II and PDGF-BB stimulate beta(1)-integrin-mediated adhesion and spreading in human VSMCs. Hypertension 35: 255-261, 2000.

33. Olivares-Navarrete R, Hyzy SL, Park JH, et al: Mediation of osteogenic differentiation of human mesenchymal stem cells on titanium surfaces by a Wnt-integrin feedback loop. Biomaterials 32: 6399-6411, 2011.

34. Régent M, Planus E, Bouin AP, et al: Specificities of $\beta 1$ integrin signaling in the control of cell adhesion and adhesive strength. Eur J Cell Biol 90: 261-269, 2011. 